Article

\title{
Reduction of Schottky Barrier Height at Graphene/Germanium Interface with Surface Passivation
}

\author{
Jules Courtin, Alain Moréac, Gabriel Delhaye, Bruno Lépine, Sylvain Tricot, Pascal Turban $\mathbb{D}$, \\ Philippe Schieffer and Jean-Christophe Le Breton* \\ Univ Rennes, CNRS, IPR (Institut de Physique de Rennes)_UMR 6251, F-35000 Rennes, France; \\ jules.courtin@univ-rennes1.fr (J.C.); alain.moreac@univ-rennes1.fr (A.M.); \\ gabriel.delhaye@univ-rennes1.fr (G.D.); bruno.lepine@univ-rennes1.fr (B.L.); \\ sylvain.tricot@univ-rennes1.fr (S.T.); pascal.turban@univ-rennes1.fr (P.T.); \\ philippe.schieffer@univ-rennes1.fr (P.S.) \\ * Correspondence: jean-christophe.lebreton@univ-rennes1.fr
}

Received: 29 October 2019; Accepted: 14 November 2019; Published: 21 November 2019

\begin{abstract}
Fermi level pinning at metal/semiconductor interfaces forbids a total control over the Schottky barrier height. 2D materials may be an interesting route to circumvent this problem. As they weakly interact with their substrate through Van der Waals forces, deposition of 2D materials avoids the formation of the large density of state at the semiconductor interface often responsible for Fermi level pinning. Here, we demonstrate the possibility to alleviate Fermi-level pinning and reduce the Schottky barrier height by the association of surface passivation of germanium with the deposition of 2D graphene.
\end{abstract}

Keywords: graphene; germanium; Schottky; photoemission; surface passivation

\section{Introduction}

Combinations of two-dimensional materials and bulk three-dimensional semiconductors have gained considerable attention lately, owing to potential new device concepts. Most studies focused on the properties of graphene/silicon (G/Si) Schottky junctions [1]. Many different new functionalities were observed such as bias-controlled Schottky barrier height [2,3] (SBH), photodetectors [4-9] or solar cells [10-12]. When covered with a metal, Metal/G/Si can be used as an efficient spin injector [13,14] or a low-resistance contact $[15,16]$. The reduction of the Si SBH is made possible by simultaneous etching of the silicon oxide and hydrogen passivation of the surface with graphene already on top [17]. In that case, the hydrogen passivation of $\mathrm{Si}$ is protected during metallization. This results in alleviation of the Fermi-level (FL) pinning and a low SBH. It is, therefore, possible to strongly reduce the SBH and associated contact resistance on moderately doped Si without any thermal treatment, or heavy doping at the interface.

Because of similar FL pinning issues, it is very challenging to realize low-resistance contacts to n-type Ge. Reduction of the SBH is particularly important for the realization of ohmic contacts or for impedance matching for spin injection $[18,19]$. In order to alleviate the FL pinning, different strategies such as Ge surface passivation through wet chemicals $[20,21]$ or deposition of a thin insulator layer on Ge surfaces have been employed [22-27].

The aim of this work is to obtain a low SBH for electrons in graphene/Ge junctions using a similar strategy as for graphene/Si junctions: to associate graphene with surface passivation of the semiconductor in order to alleviate FL pinning and reduce the SBH. For that purpose, we used X-ray Photoemission Spectroscopy (XPS) to study the interface between physico-chemistry and band 
alignments of graphene/germanium contacts and to show the possibility to modify the SBH via wet chemical passivation of the underlying germanium. We then observed the effect of the modification of the graphene work function by gold deposition on the SBH of the junction.

\section{Materials and Methods}

Intrinsic Ge (001) samples were degreased in ethanol for $30 \mathrm{~min}$, then successively dipped in a dilute $\mathrm{HCl}$ bath $\left(\mathrm{HCl}: \mathrm{H}_{2} \mathrm{O}, 1: 4\right)$ for $30 \mathrm{~s}$ and a $\mathrm{H}_{2} \mathrm{O}_{2}$ bath $\left(\mathrm{H}_{2} \mathrm{O}_{2}: \mathrm{H}_{2} \mathrm{O}, 1: 10\right)$ for $60 \mathrm{~s}$, three times each. The surface oxide was then etched one last time in $\mathrm{HCl}$ followed by a final oxidizing step in $\mathrm{NH}_{4} \mathrm{OH}: \mathrm{H}_{2} \mathrm{O}_{2}: \mathrm{H}_{2} \mathrm{O}$ (1:2:10). For the realization of graphene/germanium contacts, monolayer CVD-graphene grown on $\mathrm{Cu}$ was purchased from Graphenea $($. A $200 \mathrm{~nm}$ polymethyl methacrylate (PMMA) layer was spin-coated on top of the $\mathrm{G} / \mathrm{Cu}$ to serve as a mechanical support layer during transfer. The $\mathrm{Cu}$ was then etched in a $\mathrm{FeCl}_{3}$ solution until no $\mathrm{Cu}$ could be seen and the floating PMMA/G was rinsed in several water and diluted $\mathrm{HCl}$ baths in order to eliminate metallic residues. After rinsing, the PMMA/G was transferred onto the Ge wafer and left to dry overnight. After transfer and drying, the PMMA resist was cleaned in acetone and the sample was introduced under ultra-high vacuum (UHV) with a base pressure of $10^{-10}$ Torr for a $3 \mathrm{~h}$ annealing at $30{ }^{\circ} \mathrm{C}$ in order to remove resist residues. After annealing, the sample was taken out of UHV for a wet passivation step either in $\mathrm{HF}(10 \%)$ for $10 \mathrm{~min}$ for hydrogen passivation (hereafter named $\mathrm{Ge}: \mathrm{H}$ ) or in dilute $7.5 \% \mathrm{HCl}$ for $30 \mathrm{~s}$ for $\mathrm{Cl}$ passivation (hereafter named $\mathrm{Ge}: \mathrm{Cl}$ ).

We used X-ray photoemission spectroscopy (XPS) to study the physico-chemistry of the G/Ge contacts with different Ge surface treatments before and after gold deposition. Measurements were realized at normal emission and room temperature using a $\operatorname{MgK} \alpha(1253.6 \mathrm{eV}) \mathrm{X}$-ray source. The kinetic energy of the emitted electrons was measured by employing a hemispherical analyzer (Omicron EA125) with a five-channel detection system. The total energy resolution was $0.80 \mathrm{eV}$. Before photoemission measurement, the analyzer was calibrated with a thick gold sample. We assume an energy difference of $84.0 \mathrm{eV}$ between the Au4f7/2 peak and the Fermi level [28].

\section{Results}

Figure 1 shows the Ge3d core level after $3 \mathrm{~h}$ annealing in UHV for the G/Ge samples. The experimental spectra were decomposed after background correction with a least-square procedure using a Lorentzian convoluted with a Gaussian to represent each of the spin-orbit-split components of the Ge3d core level. In the fitting procedure, the spin-orbit splitting of the Ge3d core level was fixed at $0.58 \mathrm{eV}$ and the branching ratio was taken to be the statistical value of 3:2. The same spin-orbit-split and branching ratio were used for the various components introduced in our fitting procedure. The main peak at $29.64 \mathrm{eV}$ for $\mathrm{G} / \mathrm{Ge}$ and $29.60 \mathrm{eV}$ for Ge is attributed to bulk Ge. Other peaks located at $0.9 \mathrm{eV}$, $1.6 \mathrm{eV}, 2.6 \mathrm{eV}$ and $3.4 \mathrm{eV}$ from the main peak correspond to the photoemission signal from germanium in an oxidation state of $+1,+2,+3$ and +4 , respectively [29].

After HF etching, only the +1 oxidation component is observable for the Ge sample, while for $\mathrm{G} / \mathrm{Ge}$ the +1 and +2 oxidation states are visible. This indicates that HF removed most of the oxide but that the etching efficiency and/or kinetics in HF are reduced by the presence of graphene on the surface in opposition to what we observed on silicon, where oxide removal is not affected by the presence of graphene [17]. The deposition of $1 \mathrm{~nm} \mathrm{Au}$ on the Ge surface induces a $0.25 \mathrm{eV}$ shift of the main Ge3d component towards lower binding energies (BE). This shift indicates that the gold deposition induces a band bending change as the $\mathrm{Au} / \mathrm{Ge}$ interface forms. For the graphene-covered sample, no binding energy shift was observed after the deposition of gold, indicating that no further band bending took place.

Because of the greater bond strength of $\mathrm{Ge}-\mathrm{Cl}$ over $\mathrm{Ge}-\mathrm{H}$, chloride passivation is expected to be more stable than hydrogen [30]. As Ge oxides are soluble in $\mathrm{HCl}$, etching in $\mathrm{HCL}$ would remove the oxide and passivate the surface with chloride. We can see in Figure 2 an almost similar shape of the Ge3d spectra between graphene-covered and -uncovered surfaces. Here, in the photoemission 
spectra, we observe only a contribution from Ge atoms in oxidation state +1 in addition to the Ge bulk component. This indicates that either the oxide removal is not complete in $\mathrm{HCl}$ or the surface re-oxidizes before introduction under UHV. We confirm in our survey spectrum that $\mathrm{Cl}$ ions are still present at the surface after introduction of the sample in UHV. After the deposition of $1 \mathrm{~nm} \mathrm{Au}$ on the $\mathrm{Ge}: \mathrm{Cl}$ surface, we observe a $0.34 \mathrm{eV}$ shift towards lower binding energies of the Ge3d bulk component. The final BE position of the main Ge3d peak is essentially the same as for the $\mathrm{Au} / \mathrm{Ge}: \mathrm{H}$ sample. When the surface is protected with graphene the shift of the Ge3d main component is only $0.19 \mathrm{eV}$.

$\mathrm{G} / \mathrm{Ge}: \mathrm{H}$

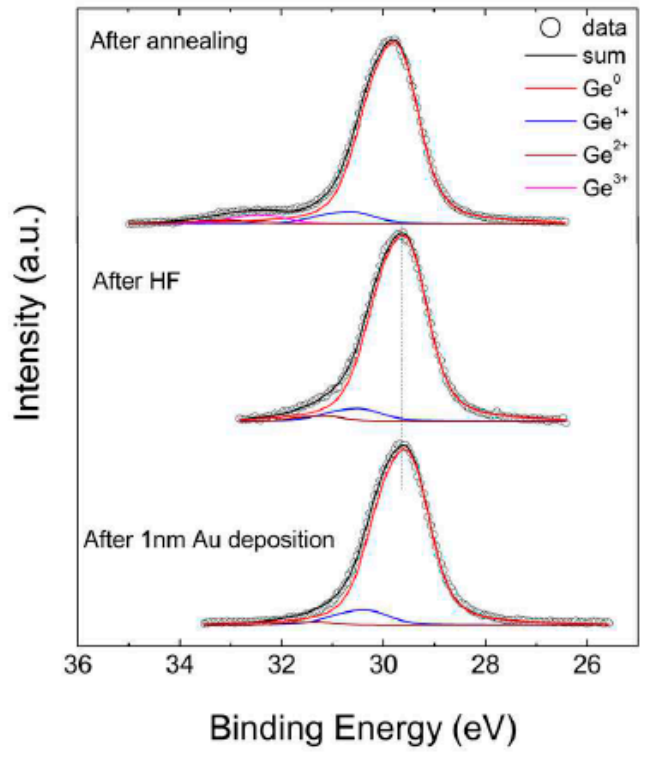

Ge:H

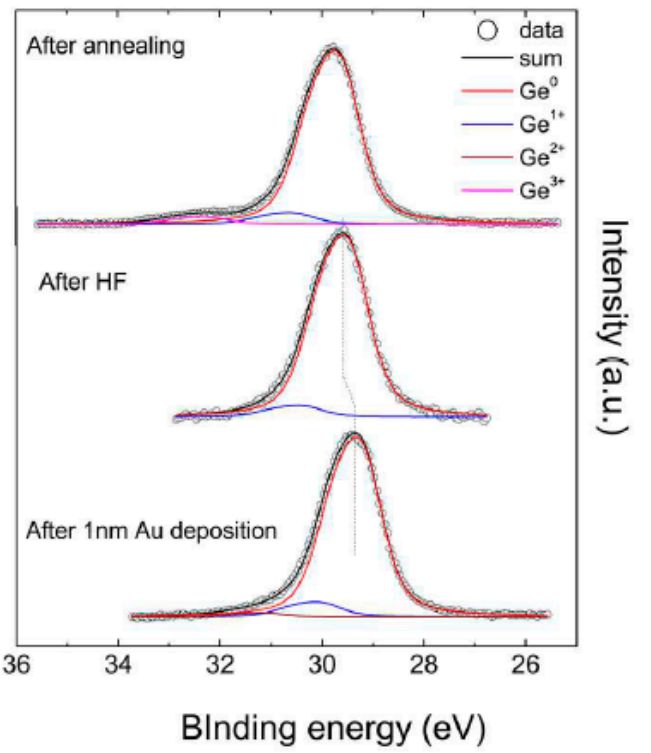

Figure 1. Ge3d core level of G/Ge:H and Ge:H samples after annealing for $3 \mathrm{~h}$ under vacuum, after 10 mins in HF (10\%) and after $1 \mathrm{~nm}$ Au deposition.

G/Ge:Cl

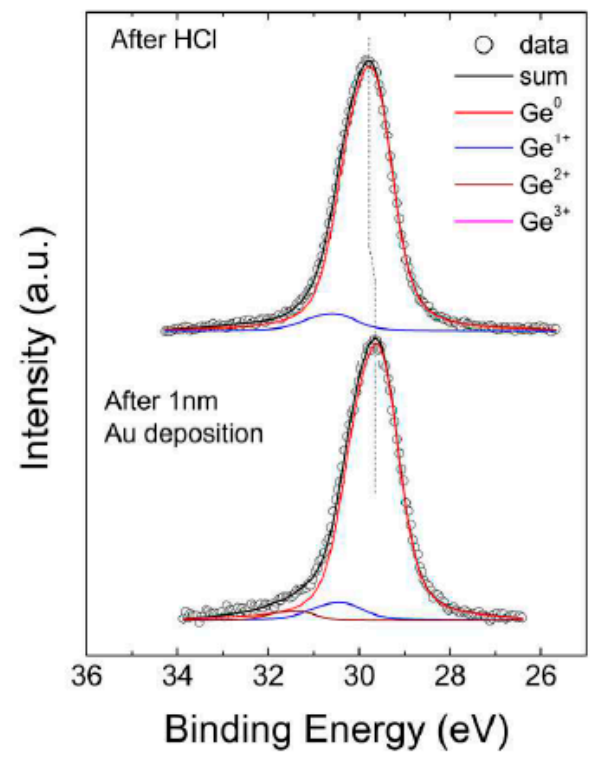

$\mathrm{Ge}: \mathrm{Cl}$

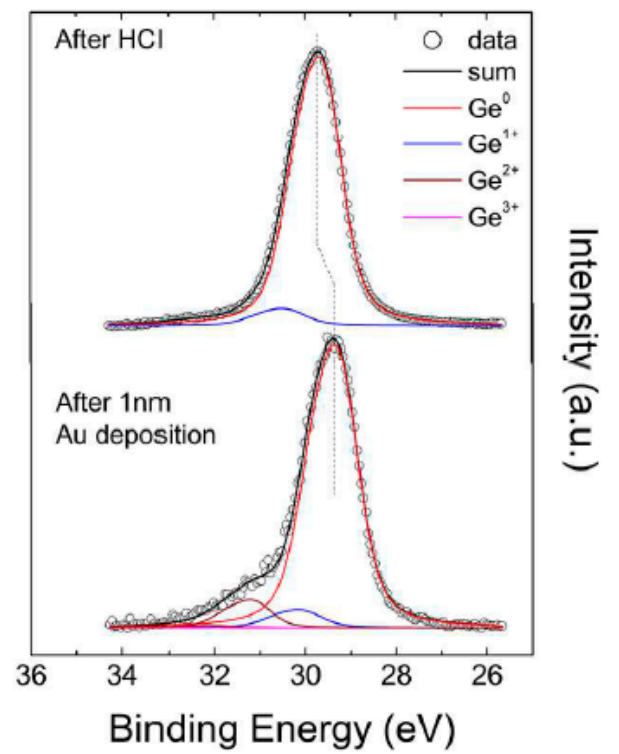

Figure 2. Ge3d core level of $\mathrm{G} / \mathrm{Ge}: \mathrm{Cl}$ and $\mathrm{Ge}: \mathrm{Cl}$ samples after $30 \mathrm{~s}$ in $\mathrm{HCl}(7.5 \%)$ and after $1 \mathrm{~nm}$ Au deposition. 
Figure 3 shows the experimental spectrum of the $\mathrm{C} 1$ s core level for single-layer graphene on Ge passivated with $\mathrm{HCl}$ and $\mathrm{HF}$. A main component corresponds to $\mathrm{C}-\mathrm{C}$ sp2 bonds and a second component located at $0.7 \mathrm{eV}$ higher $\mathrm{BE}$ is attributed to $\mathrm{sp} 3$ carbons [31]. One more component at a $2.4 \mathrm{eV}$ higher $\mathrm{BE}$ (labelled $\mathrm{C} 1$ on the figure) is assigned to the contribution of carbon atoms from PMMA residues [32]. It can be seen that the deposition of $1 \mathrm{~nm}$ of $\mathrm{Au}$ on graphene causes a $\mathrm{C} 1 \mathrm{~s}$ core level shift towards lower BE of 0.18 and $0.10 \mathrm{eV}$ for $\mathrm{Ge}: \mathrm{Cl}$ and Ge:H samples, respectively. This shift is induced by an electron transfer from graphene toward $\mathrm{Au}$ at the graphene/Au interface [33].
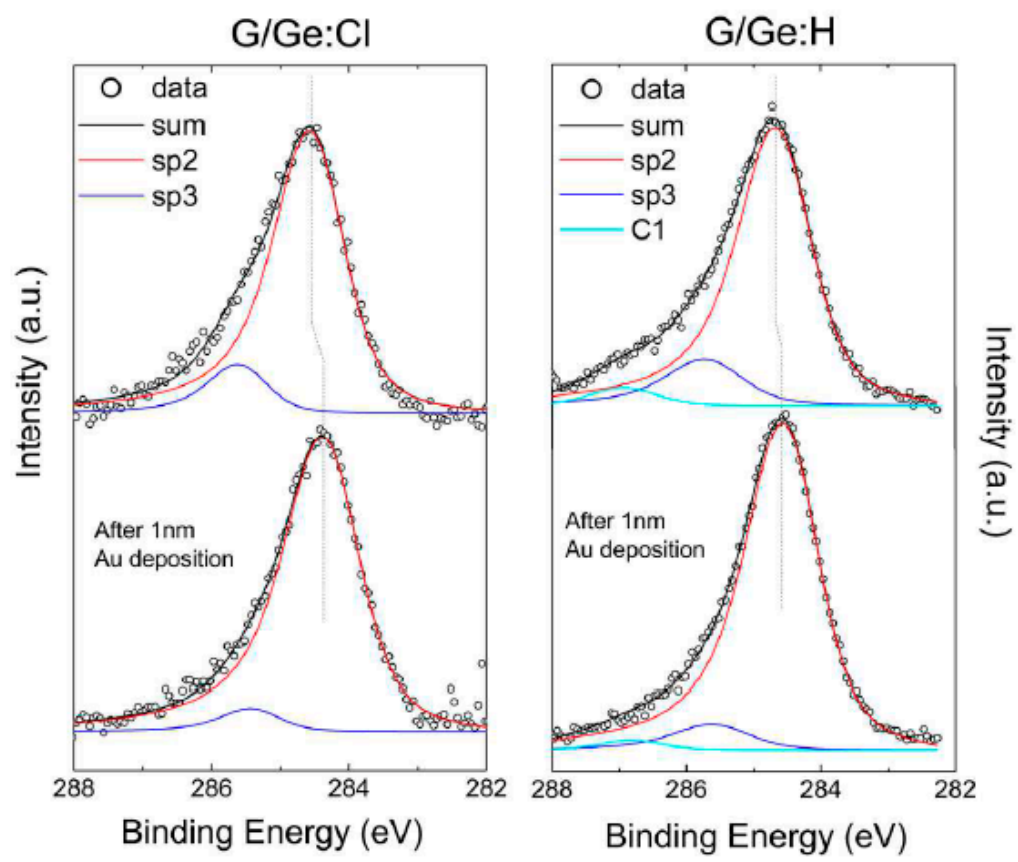

Figure 3. C1s core level of the graphene-covered regions for HF- and HCl-passivated Ge surfaces before and after $1 \mathrm{~nm}$ Au deposition.

\section{Discussion}

From the position of the main Ge3d peak, we can determine the Schottky barrier height for electrons, defined as the difference in energy between the Fermi level and the conduction band minimum at the interface, with the following equation:

$$
\phi_{B}=\left(\Delta(V B-G e 3 d)+E_{g}\right)-B E^{G e 3 d}
$$

where $\Delta(V B-G e 3 d)$ is the energy difference between the Ge3d core level and the valence band, $E_{g}$ is the Ge bandgap and $B E(G e 3 d)$ is the measured binding energy of the Ge3d core level referenced to the Fermi level. $\Delta(V B-G e 3 d)$ is set to $29.30 \mathrm{eV}$ [25] and the Ge bandgap to $0.67 \mathrm{eV}$. The measured SBHs are summarized in Table 1 as a function of the surface treatment.

Table 1. Schottky Barrier Height (in eV) for various Ge surface treatments.

\begin{tabular}{lccc}
\hline Surface Treatment & G/Ge & Au/G/Ge & Au/Ge \\
\hline $\mathrm{HF}$ & 0.49 & 0.53 & 0.78 \\
$\mathrm{HCl}$ & 0.31 & 0.50 & 0.77 \\
\hline
\end{tabular}

Table 1 summarizes the SBH of our heterostructures with different surface treatments with and without graphene and before and after Au deposition. We can notice that the $\mathrm{SBH}$ of intimate $\mathrm{Au} / \mathrm{Ge}$ interfaces is independent of the Ge surface treatment. These SBH values are close to previous reports for $\mathrm{Au} / \mathrm{Ge}$ contacts [34]. For metal/Ge interfaces, the FL is strongly pinned close to the valence band 
edge. Indeed the SBH only weakly depends on the metal work function ranging from 0.49 to $0.67 \mathrm{eV}$ for metal work functions variations of $2.8 \mathrm{eV}$ [35]. The introduction of a graphene monolayer between $\mathrm{Au}$ and Ge strongly reduces the SBH to about $0.5 \mathrm{eV}$. This behavior suggests that the FL pinning was alleviated by the presence of graphene at the interface.

An even lower SBH value of $0.31 \mathrm{eV}$ was obtained for graphene on a $\mathrm{HCl}$-treated Ge surface. This is a strong indication that the chloride passivation was efficient in reducing the surface state density and that the FL is not pinned. In that case, we can apply the simple model of Schottky-Mott where the $\mathrm{SBH} \phi_{\mathrm{B}}$ is:

$$
\phi_{\mathrm{B}}=\mathrm{W}_{\mathrm{G}}-\chi_{\mathrm{Ge}}
$$

with $W_{G}$ the work function of graphene and $\chi_{G e}$ the electronic affinity of the semiconductor. Lin et al. [36] measured a $\mathrm{W}_{\mathrm{G}}$ of $4.3 \mathrm{eV}$ for CVD-graphene deposited via a PMMA-assisted method similar to ours. This value is lower than the commonly used $4.54 \mathrm{eV}$ because of resist contamination and structural defects induced during wet transfer. With an electron affinity of $4.0 \mathrm{eV}$ for $\mathrm{Ge}$, this would lead to an $\mathrm{SBH}$ of $0.30 \mathrm{eV}$, in excellent agreement with our result. For an un-passivated surface, the FL is expected to be pinned close to the charge neutrality level ( $0.09 \mathrm{eV}$ above the valence band maximum [35]). In that case, Dimoulas et al. [35] predict an SBH of $0.56 \mathrm{eV}$ for a graphene/Ge contact. The SBH for G/Ge:H is between these two values, suggesting a less efficient passivation of $\mathrm{HF}$ compared to $\mathrm{HCl}$. This is expected since the hydrogen passivation is not stable in air and hydrogen is removed from the surface within a few minutes [37]. Xu et al. [38] showed on G/Si:H that the dominant interaction between graphene- and hydrogen-passivated Si surfaces is through Van der Waals forces. In that case, C and Si atoms do not interact with each other. Depassivation of $\mathrm{Si}$ induced a stronger interaction between $\mathrm{Si}$ and $\mathrm{C}$ atoms, eventually leading to the formation of covalent bonds and an increased density of states in the gap of Si. The situation is similar here, with a weak interaction between $\mathrm{C}$ and Ge atoms associated with a low density of states in the Ge bandgap when passivation is efficient (Cl-passivation). When the passivation is less efficient (H-passivation), the interaction between $\mathrm{C}$ and $\mathrm{Ge}$ atoms becomes stronger and the density of states in the Ge gap increases.

As gold is deposited on the $\mathrm{G} / \mathrm{Ge}: \mathrm{Cl}$ surface, the $\mathrm{SBH}$ increases by $0.19 \mathrm{eV}$. At the same time, the work function of graphene is increased by an almost similar value of $0.18 \mathrm{eV}$. This is another strong indication that the FL is unpinned at the Ge surface. A similar gold deposition weakly modifies the $\mathrm{SBH}$ for $\mathrm{G} / \mathrm{Ge}: \mathrm{H}$, supporting our interpretation of a more pinned FL due to a less efficient hydrogen passivation.

\section{Conclusions}

We studied the physico-chemistry and band alignments of G/Ge surfaces with different passivation treatments of the Ge surface by photoemission spectroscopy. We observed an almost complete removal of the surface oxides by wet chemical etching in HF or HCl. These wet etchings were efficient even with the graphene layer on the surface. When Au is deposited on Ge, the SBH is essentially independent of the surface treatment, as expected for strongly pinned FL at metal/Ge contacts. We observe a reduction of the SBH by the insertion of a graphene monolayer between $\mathrm{Au}$ and $\mathrm{Ge}$, suggesting an alleviation of the FL. An even stronger alleviation is induced by chloride passivation. In that case, we reach the Schottky limit. The association of graphene with an efficient surface passivation could lead to a low SBH on n-type Ge.

Author Contributions: Conceptualization, J.C. and J.-C.L.B.; Data curation, J.C. and J.-C.L.B.; Formal analysis, J.C., A.M. and J.-C.L.B.; Funding acquisition, P.S. and J.-C.L.B.; Investigation, J.-C.L.B.; Methodology, J.C., G.D., B.L., P.S. and J.-C.L.B.; Project administration, P.T., P.S. and J.-C.L.B.; Resources, S.T.; Supervision, P.S. and J.-C.L.B.; Validation, J.-C.L.B.; Writing—original draft, J.-C.L.B.; Writing—review \& editing, P.S.

Funding: This research was funded by the Agence Nationale de la Recherche (ANR). We acknowledge the support from the French National Research Agency (ANR) FEOrgSpin project (Grant No. ANR-18-CE24-0017-01).

Conflicts of Interest: The authors declare no conflict of interest. 


\section{References}

1. Di Bartolomeo, A. Graphene Schottky Diodes: An Experimental Review of the Rectifying Graphene/Semiconductor Heterojunction. Phys. Rep. 2016, 606, 1-58. [CrossRef]

2. Yang, H.; Heo, J.; Park, S.; Song, H.J.; Seo, D.H.; Byun, K.-E.; Kim, P.; Yoo, I.; Chung, H.-J.; Kim, K. Graphene Barristor, a Triode Device with a Gate-Controlled Schottky Barrier. Science 2012, 336, 1140-1143. [CrossRef] [PubMed]

3. Ojeda-Aristizabal, C.; Bao, W.; Fuhrer, M.S. Thin-Film Barristor: A Gate-Tunable Vertical Graphene-Pentacene Device. Phys. Rev. B Condens. Matter Mater. Phys. 2013, 88, 3-6. [CrossRef]

4. An, Y.; Behnam, A.; Pop, E.; Ural, A. Metal-Semiconductor-Metal Photodetectors Based on Graphene/p-Type Silicon Schottky Junctions. Appl. Phys. Lett. 2013, 102, 013110. [CrossRef]

5. Goykhman, I.; Sassi, U.; Desiatov, B.; Mazurski, N.; Milana, S.; De Fazio, D.; Eiden, A.; Khurgin, J.; Shappir, J.; Levy, U.; et al. On-Chip Integrated, Silicon-Graphene Plasmonic Schottky Photodetector with High Responsivity and Avalanche Photogain. Nano Lett. 2016, 16, 3005-3013. [CrossRef]

6. Casalino, M.; Sassi, U.; Goykhman, I.; Eiden, A.; Lidorikis, E.; Milana, S.; De Fazio, D.; Tomarchio, F.; Iodice, M.; Coppola, G.; et al. Vertically Illuminated, Resonant Cavity Enhanced, Graphene-Silicon Schottky Photodetectors. ACS Nano 2017, 11, 10955-10963. [CrossRef]

7. Amirmazlaghani, M.; Raissi, F.; Habibpour, O.; Vukusic, J.; Stake, J. Graphene-Si Schottky IR Detector. IEEE J. Quantum Electron. 2013, 49, 589-594. [CrossRef]

8. Luongo, G.; Giubileo, F.; Genovese, L.; Iemmo, L.; Martucciello, N.; Di Bartolomeo, A. I-V and C-V Characterization of a High-Responsivity Graphene/Silicon Photodiode with Embedded MOS Capacitor. Nanomaterials 2017, 7, 158. [CrossRef]

9. Luongo, G.; Di Bartolomeo, A.; Giubileo, F.; Chavarin, C.A.; Wenger, C. Electronic Properties of Graphene/p-Silicon Schottky Junction. J. Phys. D Appl. Phys. 2018, 51, 255305. [CrossRef]

10. Li, X.; Zhu, H.; Wang, K.; Cao, A.; Wei, J.; Li, C.; Jia, Y.; Li, Z.; Li, X.; Wu, D. Graphene-on-Silicon Schottky Junction Solar Cells. Adv. Mater. 2010, 22, 2743-2748. [CrossRef]

11. Miao, X.; Tongay, S.; Petterson, M.K.; Berke, K.; Rinzler, A.G.; Appleton, B.R.; Hebard, A.F. High Efficiency Graphene Solar Cells by Chemical Doping. Nano Lett. 2012, 12, 2745-2750. [CrossRef]

12. Song, Y.; Li, X.; Mackin, C.; Zhang, X.; Fang, W.; Palacios, T.; Zhu, H.; Kong, J. Role of Interfacial Oxide in High-Efficiency Graphene-Silicon Schottky Barrier Solar Cells. Nano Lett. 2015, 15, 2104-2110. [CrossRef]

13. Van't Erve, O.M.J.; Friedman, A.L.; Cobas, E.; Li, C.H.; Robinson, J.T.; Jonker, B.T. Low-Resistance Spin Injection into Silicon Using Graphene Tunnel Barriers. Nat. Nanotechnol. 2012, 7, 737-742. [CrossRef]

14. Van't Erve, O.M.J.; Friedman, A.L.; Cobas, E.; Li, C.H.; Hanbicki, A.T.; McCreary, K.M.; Robinson, J.T.; Jonker, B.T. A Graphene Solution to Conductivity Mismatch: Spin Injection from Ferromagnetic Metal/Graphene Tunnel Contacts into Silicon. J. Appl. Phys. 2013, 113, 17C502. [CrossRef]

15. Lee, M.H.; Cho, Y.; Byun, K.E.; Shin, K.W.; Nam, S.G.; Kim, C.; Kim, H.; Han, S.A.; Kim, S.W.; Shin, H.J.; et al. Two-Dimensional Materials Inserted at the Metal/Semiconductor Interface: Attractive Candidates for Semiconductor Device Contacts. Nano Lett. 2018, 18, 4878-4884. [CrossRef]

16. Courtin, J.; Le Gall, S.; Chretien, P.; Moréac, A.; Delhaye, G.; Lépine, B.; Tricot, S.; Turban, P.; Schieffer, P.; Le Breton, J.-C. Low Schottky Barrier Height and Transport Mechanism in Gold-Graphene-Silicon (001) Heterojunctions. Nanoscale Adv. 2019, 1, 3372-3378. [CrossRef]

17. Le Breton, J.C.; Tricot, S.; Delhaye, G.; Lépine, B.; Turban, P.; Schieffer, P. Band Alignments in Fe/Graphene/Si (001) Junctions Studied by x-Ray Photoemission Spectroscopy. Appl. Phys. Lett. 2016, 109, 051601. [CrossRef]

18. Cantoni, M.; Petti, D.; Rinaldi, C.; Bertacco, R. Bandstructure Line-up of Epitaxial Fe/MgO/Ge Heterostructures: A Combined x-Ray Photoelectron Spectroscopy and Transport Study. Appl. Phys. Lett. 2011, 98, 032104. [CrossRef]

19. Jain, A.; Louahadj, L.; Peiro, J.; Le Breton, J.C.; Vergnaud, C.; Barski, A.; Beigné, C.; Notin, L.; Marty, A.; Baltz, V.; et al. Electrical Spin Injection and Detection at $\mathrm{Al}_{2} \mathrm{O}_{3} / \mathrm{n}$-Type Germanium Interface Using Three Terminal Geometry. Appl. Phys. Lett. 2011, 99, 162102. [CrossRef]

20. Thathachary, A.V.; Bhat, K.N.; Bhat, N.; Hegde, M.S. Fermi Level Depinning at the Germanium Schottky Interface through Sulfur Passivation. Appl. Phys. Lett. 2010, 96, 152108. [CrossRef]

21. Maeda, T.; Takagi, S.; Ohnishi, T.; Lippmaa, M. Sulfur Passivation of Ge $\left(\begin{array}{lll}0 & 0\end{array}\right)$ Surfaces and Its Effects on Schottky Barrier Contact. Mater. Sci. Semicond. Process. 2006, 9, 706-710. [CrossRef] 
22. Roy, A.M.; Lin, J.Y.J.; Saraswat, K.C. Specific Contact Resistivity of Tunnel Barrier Contacts Used for Fermi Level Depinning. IEEE Electron Device Lett. 2010, 31, 1077-1079. [CrossRef]

23. Roy, A.M.; Lin, J.; Saraswat, K.C. The Effect of Fixed Charge in Tunnel-Barrier Contacts for Fermi-Level Depinning in Germanium. IEEE Electron Device Lett. 2012, 33, 761-763. [CrossRef]

24. Zhou, Y.; Ogawa, M.; Han, X.; Wang, K.L. Alleviation of Fermi-Level Pinning Effect on Metal/Germanium Interface by Insertion of an Ultrathin Aluminum Oxide. Appl. Phys. Lett. 2008, 93, 202105. [CrossRef]

25. Nishimura, T.; Kita, K.; Toriumi, A. A Significant Shift of Schottky Barrier Heights at Strongly Pinned Metal/Germanium Interface by Inserting an Ultra-Thin Insulating Film. Appl. Phys. Express 2008, 1, 051406. [CrossRef]

26. Khurelbaatar, Z.; Kil, Y.H.; Yun, H.J.; Shim, K.H.; Nam, J.T.; Kim, K.S.; Lee, S.K.; Choi, C.J. Modification of Schottky Barrier Properties of Au/n-Type Ge Schottky Barrier Diode Using Monolayer Graphene Interlayer. J. Alloys Compd. 2014, 614, 323-329. [CrossRef]

27. Kobayashi, M.; Kinoshita, A.; Saraswat, K.; Wong, H.S.P.; Nishi, Y. Fermi Level Depinning in Metal/Ge Schottky Junction for Metal Source/Drain Ge Metal-Oxide-Semiconductor Field-Effect-Transistor Application. J. Appl. Phys. 2009, 105, 023702. [CrossRef]

28. Seah, M.P. Letters to the Editor. Surf. Interface Anal. 1989, 14, 488. [CrossRef]

29. Schmeisser, D.; Schnell, R.D.; Bogen, A.; Himpsel, F.J.; Rieger, D.; Landgren, G.; Morar, J.F. Surface Oxidation States of Germanium. Surf. Sci. 1986, 172, 455-465. [CrossRef]

30. Lu, Z.H. Air-Stable Cl-Terminated Ge(111). Appl. Phys. Lett. 1995, 68, 520-522. [CrossRef]

31. Nikitin, A.; Näslund, L.-Å.; Zhang, Z.; Nilsson, A. C-H Bond Formation at the Graphite Surface Studied with Core Level Spectroscopy. Surf. Sci. 2008, 602, 2575-2580. [CrossRef]

32. Cunge, G.; Ferrah, D.; Petit-Etienne, C.; Davydova, A.; Okuno, H.; Kalita, D.; Bouchiat, V.; Renault, O. Dry Efficient Cleaning of Poly-Methyl-Methacrylate Residues from Graphene with High-Density $\mathrm{H}_{2}$ and $\mathrm{H}_{2}-\mathrm{N}_{2}$ Plasmas. J. Appl. Phys. 2015, 118, 123302. [CrossRef]

33. Giovannetti, G.; Khomyakov, P.; Brocks, G.; Karpan, V.; van den Brink, J.; Kelly, P. Doping Graphene with Metal Contacts. Phys. Rev. Lett. 2008, 101, 026803. [CrossRef]

34. Lieten, R.R.; Afanas'ev, V.V.; Thoan, N.H.; Degroote, S.; Walukiewicz, W.; Borghs, G. Mechanisms of Schottky Barrier Control on N-Type Germanium Using Ge3N4interlayers. J. Electrochem. Soc. 2011, 158, 358-362. [CrossRef]

35. Dimoulas, A.; Tsipas, P.; Sotiropoulos, A.; Evangelou, E.K. Fermi-Level Pinning and Charge Neutrality Level in Germanium. Appl. Phys. Lett. 2006, 89, 12-15. [CrossRef]

36. Lin, W.-H.; Chen, T.-H.; Chang, J.-K.; Taur, J.-I.; Lo, Y.-Y.; Lee, W.-L.; Chang, C.-S.; Su, W.-B.; Wu, C.-I. A Direct and Polymer-Free Method for Transferring Graphene Grown by Chemical Vapor Deposition to Any Substrate. ACS Nano 2014, 8, 1784-1791. [CrossRef]

37. Rivillon, S.; Chabal, Y.J.; Amy, F.; Kahn, A. Hydrogen Passivation of Germanium (100) Surface Using Wet Chemical Preparation. Appl. Phys. Lett. 2005, 87, 253101. [CrossRef]

38. Xu, Y.; He, K.T.; Schmucker, S.W.; Guo, Z.; Koepke, J.C.; Wood, J.D.; Lyding, J.W.; Aluru, N.R. Inducing Electronic Changes in Graphene through Silicon (100) Substrate Modification. Nano Lett. 2011, 11, 2735-2742. [CrossRef]

(C) 2019 by the authors. Licensee MDPI, Basel, Switzerland. This article is an open access article distributed under the terms and conditions of the Creative Commons Attribution (CC BY) license (http://creativecommons.org/licenses/by/4.0/). 